\title{
CBC e SBAIT: somando para multiplicar
}

\section{CBC and SBAIT: adding to multiply}

\author{
Gustavo Pereira Fraga, TCBC-SP1; José Eduardo Ferreira Manso, TCBC-RJ2; Sizenando Vieira Starling, tCBC-MG ${ }^{3}$
}

$\mathrm{O}$ número atual da Revista do Colégio Brasileiro de Cirurgiões (RCBC) tem tudo para entrar para a história da maior entidade de cirurgiões da América Latina. $\mathrm{O}$ Colégio Brasileiro de Cirurgiões, fundado em 1929, tem nesse periódico, publicado há mais de 80 anos e desde 1974 bimestralmente e ininterruptamente, o seu maior instrumento de divulgação da ciência em cirurgia entre os seus membros e demais leitores. A indexação na base Scielo em 2004 e no Medline / Pubmed em 2009 é um reconhecimento da excelência desse periódico e da necessidade de internacionalização. Recentemente a Coordenação de Aperfeiçoamento de Pessoal de Nível Superior (CAPES) promoveu a Revista do Colégio Brasileiro de Cirurgiões (RCBC) ao nível Qualis B1 a fim de que pesquisadores e cirurgiões do Brasil divulguem seus estudos nessa revista, a fim de intensificar e qualificar a pesquisa científica nacional.

Paralelamente a essa importante missão do CBC, uma jovem sociedade, a SBAIT (Sociedade Brasileira de Atendimento Integrado ao Traumatizado), criada em 1982 pelo Prof. Dario Birolini, da Universidade de São Paulo, e colegas, vem trabalhando para divulgar no país uma doença que ainda é negligenciada pela nossa sociedade: o trauma. A necessidade de enfrentar essa doença atinge uma amplitude cada vez maior à medida que se intensifica a parceria entre o CBC e a SBAIT.

O trauma é uma doença que apresenta características sociais, econômicas e culturais. O fato dos homicídios constituírem-se na principal causa de morte entre as causas externas reflete as desigualdades que acometem o nosso país. As mortes no trânsito muitas vezes são consequência da falta de educação, planejamento e negligência. Qual é a nossa função, como profissionais de saúde e cirurgiões, nesse cenário sombrio e por vezes desanimador?

O mundo atual passa por várias mudanças, e uma que nos orgulha é o fato do Brasil ser um país de emergente crescimento econômico, já figurando entre as grandes nações. Mas muitos de nós cirurgiões, que trabaIhamos em plantões em unidades de urgência, superlotadas, com escassez de leitos e muitas vezes de recursos de infraestrutura básica. Frequentemente não ficamos orgulhosos do nosso Sistema Único de Saúde (SUS). Sentimos sim que existe uma necessidade de aperfeiçoamento e de mudanças. É necessário um maior financiamento para a saúde, e isso inclui a assistência aos doentes traumatizados, e a valorização dos profissionais. Isso é verdade, especifica- mente, para aqueles que trabalham com urgência e emergência, onde o êxodo dos experientes e competentes profissionais é evidente. As políticas do governo federal nos últimos anos, sejam no pré hospitalar, na regulação, nas unidades de pronto atendimento e agora com a expectativa da criação da Rede de Trauma, renovam as esperanças dos cirurgiões de trauma e emergência brasileiros. Vale lembrar que nos últimos meses, representantes do CBC e SBAIT se reuniram periodicamente com outras sociedades médicas no Ministério da Saúde em Brasília para desenharem essa rede. Estamos ávidos por mudanças.

Entretanto é do nosso conhecimento que só isso não resolve e temos que fazer a lição de casa. O ensino de trauma e emergência em muitas escolas médicas e de outras profissões da saúde é muitas vezes insuficiente. As criações de disciplinas dedicadas ao trauma datam de 1987, na USP e Unicamp, mas ainda são poucas instituições que têm uma estrutura acadêmica focada nessa área. O movimento das Ligas do Trauma no Brasil, desde 1992, tendo como um dos líderes o saudoso Prof. Mario Mantovani, está em constante crescimento e é um reflexo que os acadêmicos estão ávidos por aprender. As ligas já estão sendo implantadas em outros países, como Venezuela, Paraguai e Colômbia, e o fato do CBC passar a admitir acadêmicos entre seus membros mostra essa preocupação com o futuro. Juntos, CBC e SBAIT podem multiplicar essas ações e atrair cada vez mais médicos para a área de cirurgia.

Algo que também nos preocupa é a formação desses cirurgiões. O Brasil provavelmente não precisa de mais médicos (16 mil se formam anualmente), mas sim de bons médicos. E sabemos que a residência médica é o principal momento na formação do cirurgião e um treinamento com dois anos de duração é com certeza insuficiente. Sabemos que o mercado com as diversas especialidades cirúrgicas afasta o jovem profissional da cirurgia geral e o governo, através dos Ministérios da Educação e Saúde, está atento para formar o profissional que o país necessita. O recente programa Pró-Residência, que prioriza entre outras a formação de cirurgiões na área de Cirurgia do Trauma, aponta essa necessidade, e a criação de vários programas em diferentes instituições do país revelam essa demanda reprimida. Vale ressaltar que o campo de treinamento não é só os hospitais universitários, importante é inserir esses residentes nos hospitais de ensino e no SUS, onde é atendida a grande maioria dos doentes traumatizados.

1. Universidade Estadual de Campinas (Unicamp); 2. Universidade Federal do Rio de Janeiro (UFRJ); 3. Hospital João XXIII, Belo Horizonte, MG. 
É como fruto dessa integração que surge esse número da RCBC. Desde 2009 a SBAIT vem planejando o seu X Congresso em conjunto com o XIV Congresso Brasileiro das Ligas do Trauma e a iniciativa pioneira de organizar o World Trauma Congress. Um país sede de Copa do Mundo de Futebol e Jogos Olímpicos, em evidência global, precisa organizar o seu sistema de saúde, e com muita atenção o seu sistema de trauma, ainda inexistente. Com o apoio do CBC, importantes sociedades internacionais, várias sociedades nacionais e do governo federal, do estado e município do Rio de Janeiro, surgiu o que acreditamos ser um grandioso evento. Para sedimentar essa parceria o CBC dedicou esse número de sua revista ao WTC, a fim de aumentar a produção científica em trauma, com foco no Brasil, e apresentar esse importante periódico aos aproximadamente 400 estrangeiros que participam do evento no Rio. São 72 palestrantes estrangeiros, vindos de 36 países, que se unirão a outros congressistas do exterior e aproximadamente 2500 do Brasil, com uma grande participação de acadêmicos. O mundo do trauma necessita e irá entender que apesar de algumas limitações também pratica-se, em nosso país, uma boa medicina. Além disso, também irá conhecer os nossos ligantes e compreender que o potencial desse país não está só nas riquezas naturais e no futebol.
Os leitores serão brindados com dois artigos de revisão de professores consagrados, em assuntos polêmicos como a cirurgia de controle de danos e diverticulite. Conhecerão mais aspectos da epidemiologia do trauma em diferentes regiões, métodos diagnósticos e o dilema do cirurgião: saber quando não operar, baseado em protocolos, o que resulta em menos complicações para o doente quando bem selecionados para o tratamento não operatório. Observarão que a abordagem do traumatizado é multidisciplinar, do mais básico ao mais complexo, e que na área de ensino também estamos avançando, seja na graduação ou pós graduação. E entenderão que temos que discutir a qualidade de atendimento, a organização de registros e os processos de melhoria na assistência. O Brasil precisa desse cirurgião bem capacitado, seja geral, do trauma, de emergência ou outro especialista comprometido com todos esses aspectos que essa doença necessita para ser enfrentada.

E a nossa função? Precisamos mudar esse cenário. Com a experiência dos mais antigos, a força dos jovens e a sabedoria daqueles que se desprendem das próprias vaidades, estendem as mãos e ajudam aos que mais precisam: as vítimas do trauma. Somos médicos, cirurgiões, e cremos que é somando que se multiplica. 